\title{
Mechanical Properties of Teeth Restored After Selective Caries Excavation. Systematic Review and Meta-Analysis
}

\author{
Propiedades Mecánicas de Dientes Restaurados Tras la Remoción \\ Selectiva de Caries. Revisión Sistemática y Metaanálisis
}

\author{
Camila Corral-Nuñez ${ }^{1,2}$; Hendrik Meyer-Lueckel³; Ignacio Araya-Cabello4; \\ Javier Martin ${ }^{1}$; Juan Estay ${ }^{1}$ \& Richard J. Wierichs ${ }^{3,5}$
}

\begin{abstract}
CORRAL-NÚÑEZ, C.; MEYER-LUECKEL, H.; ARAYA-CABELLO, I.; MARTIN, J.; ESTAY, J. \& WIERICHS, R. J. Mechanical properties of teeth restored after selective caries excavation. Systematic review and meta-analysis. Int. J. Odontostomat., 15(1):204-212, 2021
\end{abstract}

ABSTRACT: The aim of this study was to systematically review the literature of in vitro studies comparing the mechanical properties of teeth restored after selective caries excavation (SCE) and complete caries excavation (CCE). The PubMed/MEDLINE and EMBASE electronic databases were searched systematically. In vitro studies investigating the mechanical properties of teeth restored after SCE, were independently checked by two authors. Inclusion criteria were: (1) performing SCE (2) mentioning the teeth were later restored, and (3) evaluating mechanical properties of the restored teeth. Meta-analysis was performed with and without discriminating between shallow and deep lesions. From 1,859 potentially eligible studies, 14 were selected for full text analysis and 5 were included in the meta- analysis. Fracture resistance was significantly lower after SCE than after CCE in overall analysis (SMD[95\% Cl] $=-1.62[-3.04,-0.20]$ ) and for deep lesion $(\mathrm{SMD}[95 \% \mathrm{Cl}]=-1.62[-2.62,-0.61])$, whereas cuspal deflection at 200 and $400 \mathrm{~N}$ was significantly higher after SCE than after CCE for discriminated and non- discriminated analyses. Furthermore, for shallow lesions the risk of catastrophic fracture was significantly lower after SCE than CCE $(R R[95 \% \mathrm{Cl}]=0.58[0.43,0.78])$. The included studies presented low and medium risk of bias. The mechanical behavior of restored teeth seems to be affected by the excavation strategy. Although there is a tendency for lower fracture resistance and higher cuspal deflection after SCE, there is a lower risk of catastrophic failure when compared to CCE. However, this conclusion is based on very few in vitro studies.

KEY WORDS: teeth, mechanical properties, caries, systematic rewiew.

\section{INTRODUCTION}

The management of cavitated carious lesions involves removal of the carious tissue and placement of a restoration. In past decades complete caries excavation (CCE) was recommended based on findings that staining precedes bacterial invasion (Fusayama et al., 1966) and on the specific plaque hypothesis. However, CCE is associated with a relatively high risk of pulpal exposure and of postoperative pulpal symptoms (Ricketts et al., 2013; Schwendicke et al., 2013a). Furthermore, in the last decade the understanding of the disease has changed
(Paris \& Meyer-Lueckel, 2013). Caries is now seen as a result of the qualitative and quantitative changes within the dental biofilm to acidogenic and aciduric bacterial species (ecological plaque hypothesis). Since this ecological approach also influences the therapy (Paris \& Meyer-Lueckel), the necessity of CCE of infected dentin was questioned. Therefore, to sufficiently control the disease, firstly, the creation of an environment unfavorable to cariogenic bacteria and, secondly, selective caries excavation (SCE) are currently recommended (Paris \& Meyer-Lueckel).

\footnotetext{
${ }^{1}$ Department of Restorative Dentistry, Faculty of Dentistry, University of Chile, Santiago, Chile.

${ }^{2}$ Center for Surveillance and Epidemiology of Oral Diseases, Faculty of Dentistry, University of Chile, Santiago, Chile.

${ }^{3}$ Department of Restorative, Preventive and Pediatric Dentistry, ZMK Bern, University of Bern, Bern, Switzerland.

${ }^{4}$ Department of Surgery and Buccal and Maxillofacial Traumatology, Faculty of Dentistry, University of Chile, Santiago, Chile.

${ }^{5}$ Department of Biohybrid \& Medical Textiles, Institute of Applied Medical Engineering, RWTH Aachen University, Aachen, Germany.
}

Received: 2020-06-26 Accepted: 2020-10-05 
SCE involves excavation to hard tissue at cavity margins only. Thus, an adequate seal of the restoration can be achieved. In proximity to the pulp softened carious dentin is intentionally left in deep lesions and leathery dentin in shallow/moderately lesions (Schwendicke et al., 2016). Several studies showed that a restoration providing a good seal changes the ecologic and metabolic balance in the remaining softened carious tissue (Bjørndal \& Kidd, 2005; Maltz et al., 2012). Thus, arresting the progression of the carious lesion. However, the residual carious dentin is less elastic and, thus, might compromise the bonding of the entire restoration (Yoshiyama et al., 2002; Perdigão, 2010). Furthermore, increased cuspal deflection could compromise marginal integrity and accelerate marginal deterioration leading to microleakage or restoration/tooth fractures (Schwendicke et al., 2014b).

A systematic review on clinical studies indicated that SCE is advantageous compared with CCE. However, SCE presented similar failure rates compared to CCE (Schwendicke et al., 2013a). A similar combined risk of biological and mechanical failure was observed as well. Nonetheless, the authors also highlighted that only a few studies included non-pulpal reasons for failure. Thus, limiting the level of evidence to characterize the mechanical behavior of tooth-restoration complex in in vivo conditions (Schwendicke et al., 2013a). Contrastingly, laboratory studies allow mechanical analyses to be performed at specific loads that are ethically not feasible in clinical conditions, using standardized teeth and cavity dimensions. Furthermore, until now no quantitative data synthesis (meta-analysis) focusing on the effects on the mechanical properties of restored teeth after SCE has been published. Thus, this systematic review aimed to critically summarize and evaluate results of in vitro studies investigating the effects of SCE underneath restorations.

\section{MATERIAL AND METHOD}

Review design. This review aimed at systematically retrieving and analysing in vitro studies assessing the mechanical properties of teeth being restored following SCE and CCE. The review was conducted according to the PRISMA statement (Preferred Reporting Items for Systematic Reviews and Metaanalyses) (Page \& Moher, 2017).
Literature sources. A database search was performed in PubMed and EMBASE. One author (IAC) searched the databases (using a predefined search strategy) for articles published between January 1th 1900 and September 30th 2017. Gray literature was not evaluated. The language was not restricted.

Search strategy. The computer database search in MEDLINE via PubMed was: (("1900/01/01"[PDat]: "2017/09/30"[PDat])) AND (((("Humans"[Mesh]) AND ((()((()((()"Biomechanical Phenomena"[Mesh]) OR "Stress, Mechanical"[Mesh]) OR "Torsion, Mechanical"[Mesh]) OR "Fractures, Stress"[Mesh]) OR "Tensile Strength"[Mesh]) OR "Materials Testing"[Mesh]) OR "Surface Properties"[Mesh]) OR mechanic*[Ti/Ab]) OR Tensile[Ti/Ab])))) AND $((((((()($ "Dental Caries"[Mesh]) OR caries[ti/ab])) AND ((remo*[Title/Abstract]) OR excavat* [Title/Abstract]))) OR "Dental Cavity Preparation"[Mesh]))))))) NOT (("Inlays"[Mesh]) OR "Endodontics"[Mesh])).

For EMBASE the following search strategy was used: (((('biomechanics'/exp OR 'mechanical stress'/ $\exp$ OR 'mechanical torsion'/exp OR 'stress fracture'/exp OR 'tensile strength'/exp OR 'materials testing'/exp OR 'surface property'/exp) OR (mechanic:ti,ab OR tensile:ti,ab)) AND (('dental caries'/exp OR caries:ti,ab) AND (remo*:ti,ab OR excavat*:ti,ab))) AND 'human'/exp) NOT ('endodontics'/exp OR 'dental inlay'/exp.

The results of searches in different databases were crosschecked to eliminate duplicates.

Selection, inclusion and exclusion criteria. At first the titles and abstracts of the searched articles were examined independently by two authors (CCN and $\mathrm{JM}$, blinded to authors and journal of the studies) and selected considering the following inclusion criteria: studies (1) performing SCE (2) mentioning theteeth were latter restored, and (3) evaluating mechanical properties of the restored teeth. Then, selected studies were screened full-text.

For natural caries lesions selective excavation was defined as:

- preparation of peripheral enamel and dentin to hard dentin and

- leaving soft carious tissue over the pulp (deep lesions) or

- leaving firm "leathery" dentin in pulpal wall (shallow lesions) 
For artificial caries lesions selective excavation was defined as:

- artificially created caries lesion was only left in the pulpal wall

The following studies were excluded.

- studies that used other forms of excavation (such as non-selective excavation or ART)

- studies using a different end-point for excavation other than hardness

- studies using teeth with root caries

- editorial letters

- pilot studies

- reviews

Any disagreements in the eligibility criteria were solved by discussion and if no consensus was reached, a third author (HML) was consulted. Cross-referencing was performed to identify further relevant articles that could fulfil the inclusion criteria.

Data extraction. Two authors (CCN and JM) extracted the data by means of predefined structured tables. For each study, the following data were systematically extracted:

- type of teeth used

- type of caries lesion (artificial or natural)

- description of excavation

- restoration protocol

o if several types of resin composite materials were analyzed, one mean for selective and complete excavation was calculated

0 if the study included groups restored with resin composite and glass ionomer cements, only the data from resin composites were considered for analysis.

- post-restoration treatment

- outcomes measured: fracture resistance, percentage of defective margins, cuspal deflection and catastrophic failure

o the values for defective margins were combined if a study reported several types of percentages of defective margins (e.g. irregular margins, margins with microgaps, margins with distinctive gaps, overhangs or positive ledges). If the percentage of acceptable margins was reported only, the percentage of defective margins was obtained by subtracting it from $100 \%$.

o cuspal deflection was defined as the difference between the intercuspal distance at baseline and during loading at 200 and $400 \mathrm{~N}$.

o catastrophic failure was considered when the fracture failure was not repairable (e.g. vertical fractures or cuspal fractures extending over the CEJ) (Schwendicke et al., 2015b; Schwendicke et al., 2014b). Data was converted if other classifications were used.

- sample size and

- main result

Means and standard deviations of each mechanical property tested were extracted and tabulated. If a study did not show numeric results or if any information was missing, the corresponding author was contacted 3 times by e-mail, with 2-week intervals.

Risk of bias assessment. Two authors (IAC and RJW) independently evaluated the risk of bias. Any disagreement between the reviewers was discussed until an agreement was reached and if needed, by consulting a third author (CCN). For risk of bias assessment, the guidelines by the Cochrane Collaboration (Higgins \& Green, 2011) were slightly adapted. Risk of bias criteria being used in recent systematic reviews of in vitro studies were added (Moraes et al., 2015; Soares et al., 2016). Thus, risk of bias assessment included:

- random sequence generation

- allocation concealment

- blinding of participants and personnel

- blinding of outcome assessment

- incomplete outcome data

- selective outcome

- description of sample size calculation

- use of teeth with similar dimensions

- use of caries lesions (artificial or natural) with similar dimensions

- treatment performed by the same operator

- materials used according to the manufacturers' instructions

Data analysis. The statistical analyses were conducted in Review Manager (RevMan version 5.3 software, Cochrane Collaboration, Copenhagen, Denmark, 2014) using a random-effect method (Mantel, 1963). Statistical significance was defined as a p-value $\leq 0.05$ ( $Z$ test) and heterogeneity was assessed with 12 (Higgins \& Thompson, 2002). The number of events was considered as the number of teeth restored. Forest plots were created to illustrate the metaanalysis.

For fracture resistance, percentage of defective margins and cuspal deflection standardized mean differences (SMD) and $95 \%$ confidence intervals (95 $\% \mathrm{Cl}$ ) were calculated. For catastrophic failures risk ratios (RR) and $95 \% \mathrm{Cl}$ were calculated. The meta- 
analyses were performed with and without discriminating between shallow and deep lesions. Indirect comparisons were made when the descriptions for type of caries, restoration protocol and postrestoration aging treatment were similar.

The risk of bias was classified according to the sum of domains classified as "low risk (+)", as follows: 1- 4= high, 5-7= medium, 8-11= low.

\section{RESULTS}

1,859 articles were obtained by the search strategy (Fig. 1). 137 of them were duplicates. 14

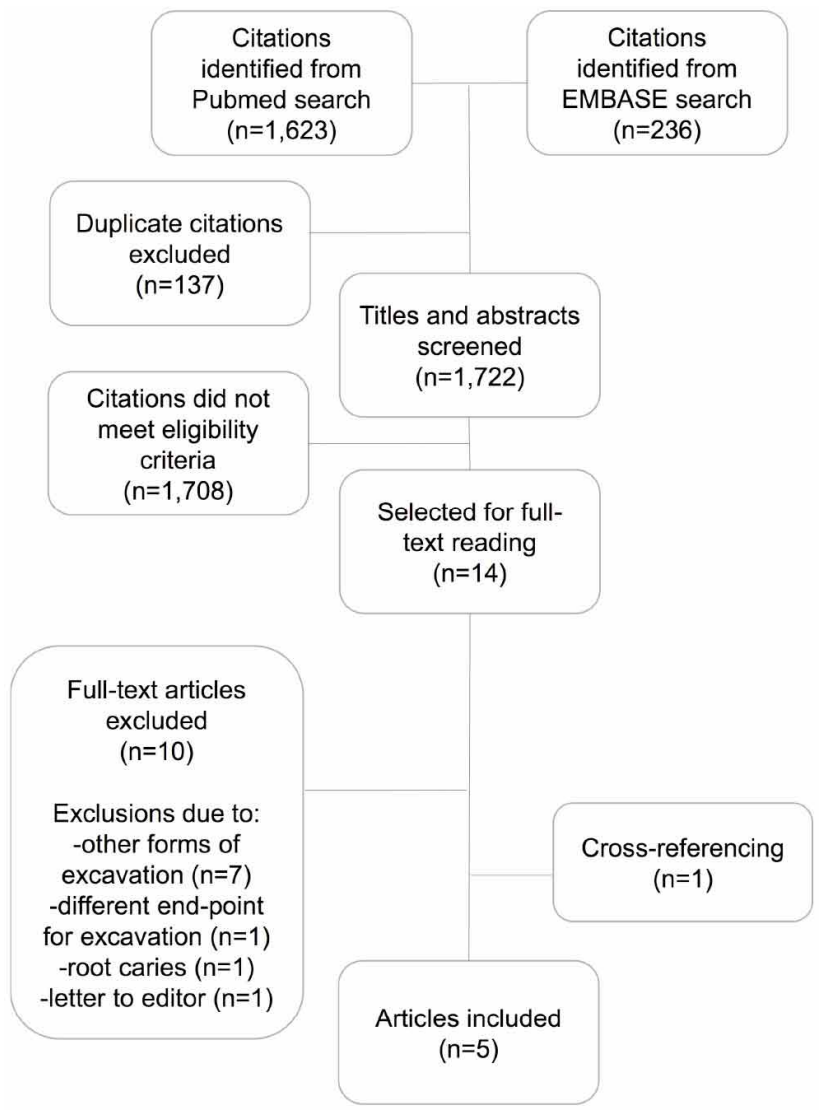

Fig. 1. PRISMA flow diagram. articles were selected for full-text reading, from which ten articles were excluded (Table I). Furthermore, one study was included by hand search. In total 5 articles were included in the systematic review and metaanalysis.

Descriptive analysis. All studies were published between 2010 and 2017, and they were all conducted in Europe. One study assessed the effect of SCE on natural caries lesions (Hevinga et al., 2010), the other four studies used healthy premolars with standardized preparations and artificial caries lesions created only in pulpal walls (Schwendicke et al., 2014a,b, 2015b, 2017).

\section{Meta-analysis}

-Fracture resistance. Three studies investigated the fracture resistance of teeth restored after SCE (Hevinga et al.; Schwendicke et al., 2014b, 2015b). A significantly lower fracture resistance after SCE compared to CCE was observed for overall analysis $(\mathrm{SMD}[95 \% \mathrm{Cl}]=$ $1.62[-3.04,-0.20])$ and in deep lesions (SMD $[95 \% \mathrm{Cl}]$ $=-1.62[-2.62,-0.61]$ ) (Fig. 2). However, data were considered heterogeneous $\left(\mathrm{I}_{\text {overall }}^{2}=91 \%\right.$; $\left.\mathrm{I}_{\text {deep }}^{2}=56 \%\right)$.

-Marginal restoration assessment.Three studies assessed the margin of restorations in standardized cavities, after thermomechanical cycling (Schwendicke et al., 2014a, 2015b, 2017). All except one study evaluated shallow lesions. Therefore, only results of shallow lesions were analyzed (Fig. 3). There was no significant difference of defective margins after SCE and CCE (SMD $[95 \% \mathrm{Cl}]=-0.28$ $[-0.64,0.07])$.

- Cuspal deflection. Two studies assessed the cuspal deflection after thermomechanical cycling (Schwendicke et al., 2014b, 2015a). Significantly higher cuspal deflection in SCE than in CCE was found in overall (at 200N SMD [95\% Cl] $=0.73[0.31$, 1.16]; at $400 \mathrm{~N}$ SMD $[95 \% \mathrm{Cl}]=0.78[0.34,1.21])$, shallow (at $200 \mathrm{~N}$ SMD $[95 \% \mathrm{Cl}]=0.75[0.26,1.25]$; at $400 \mathrm{~N} \mathrm{SMD}[95 \% \mathrm{Cl}]=1.13[0.62,1,65])$ and deep

Table I. Summary of the risk of bias assessment of included studies using a modification to the Cochrane Collaboration tool.

\footnotetext{
Hevinga et al., 2010

Schwendicke et al., 2014a

Schwendicke et al., 2014b

Schwendicke et al., 2015a

Schwendicke et al., 2017
}

(?): unclear

$(+)$ : low risk

$\begin{array}{llll}? & + & + \\ + & + & + \\ + & + & + \\ ? & + & + \\ ? & ? & +\end{array}$

(-): high risk

$\begin{array}{lllll}- & + & ? & + & + \\ - & + & + & + & + \\ + & + & + & + & + \\ + & + & ? & + & + \\ + & + & ? & + & +\end{array}$

$+$ 


\section{- Fracture resistance}

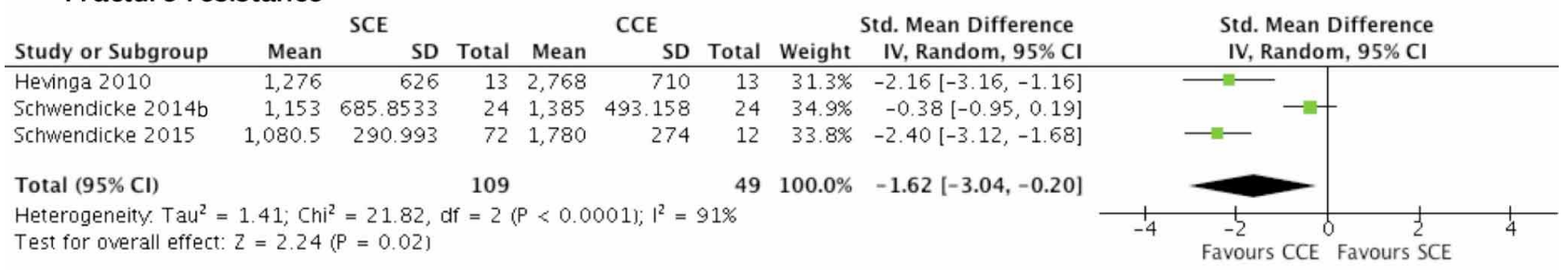

\section{- Fracture resistance in shallow lesions}

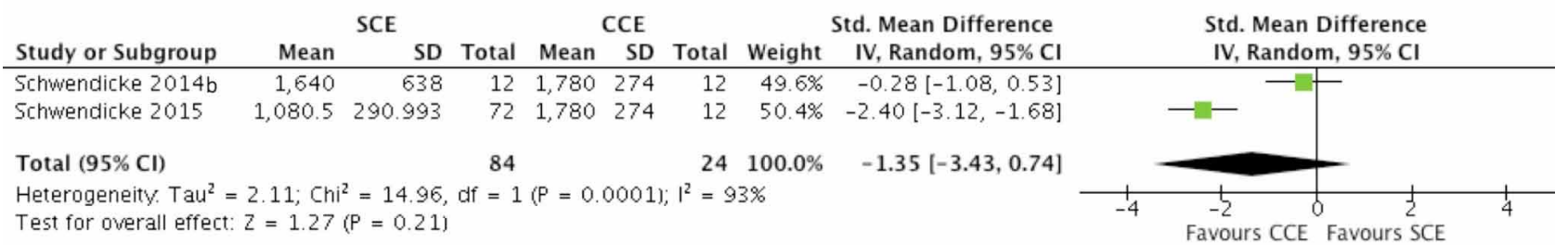

\section{- Fracture resistance in deep lesions}

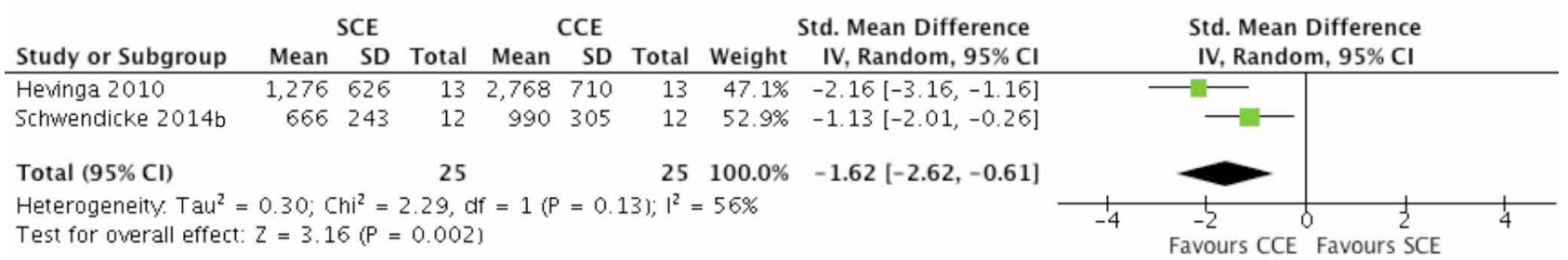

Fig. 2. Quantitative meta-analyses for fracture resistance comparing SCE vs. CCE, overall analysis and analysis according to lesion depth. SMD, $95 \% \mathrm{Cl}$, forest plots, heterogeneity parameter (I2) as well as overall statistics (Z, P) are shown.

\section{- Defective margins of shallow lesions}

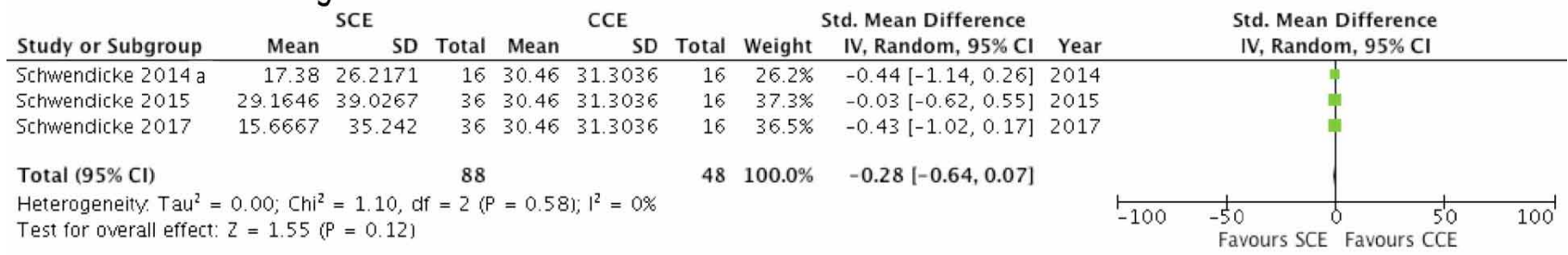

Fig. 3. Quantitative meta-analyses for defective margins comparing SCE vs. CCE. SMD, 95\%C, forest plots, heterogeneity parameter (I2) as well as overall statistics (Z, P) are shown.

lesion analyses (at 400N SMD [95 \% Cl] $=1.35[0.44$, 2.25]), except at $200 \mathrm{~N}$ in deep lesions (Fig. 4, Supplementary Fig. 1).

-Catastrophic failure. Three studies investigated the type of failure after testing resistance load failure (Hevinga et al.; Schwendicke et al., 2014b, 2015b). Data of one study had to be converted (Hevinga et al.).
For shallow lesions the risk of catastrophic fracture was significant lower after SCE than after CCE $(\mathrm{RR}[95 \% \mathrm{Cl}]=0.58[0.43,0.78])$ (Fig. 5). Furthermore, for overall analysis and for deep lesions there was a non-significant tendency for lower risk of catastrophic failure in teeth restored after selective than after complete caries excavation. However, data for these analysis were considered heterogeneous $\left(\mathrm{I}_{\text {overall }}^{2}=72 \%\right.$; $\mathrm{I}_{\text {deep }}^{2}=85 \%$ ). 
- Cuspal deflection at $400 \mathrm{~N}$

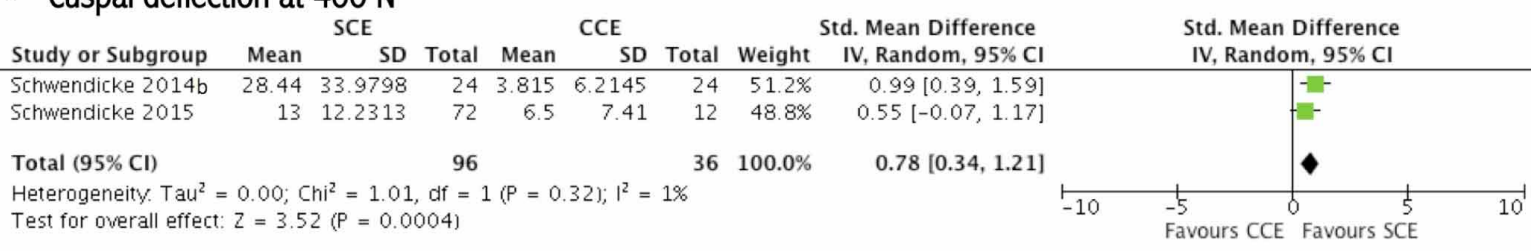

- Cuspal deflection at $400 \mathrm{~N}$ of shallow lesions

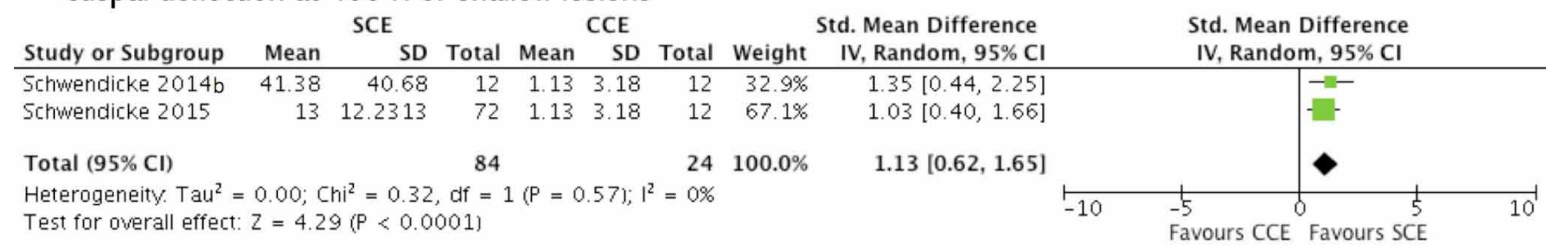

- Cuspal deflection at $400 \mathrm{~N}$ of deep lesions

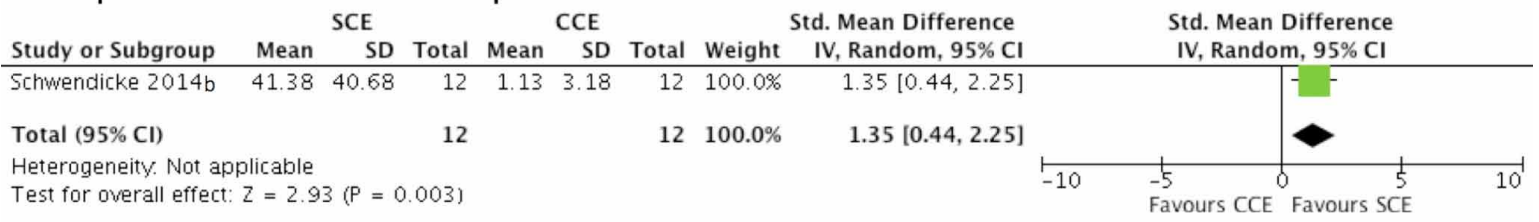

Fig. 4. Quantitative meta-analyses for cuspal deflection at $400 \mathrm{~N}$ comparing SCE vs. CCE, overall analysis and analysis according to lesion depth. $\mathrm{SMD}, 95 \% \mathrm{Cl}$, forest plots, heterogeneity parameter (I2) as well as overall statistics (Z, P) are shown.

\section{- Catastrophic fracture}

SCE

CCE

Risk Ratio

Risk Ratio

Study or Subgroup Events Total Events Total Weight $\mathrm{M}-\mathrm{H}$, Random, $95 \% \mathrm{Cl}$

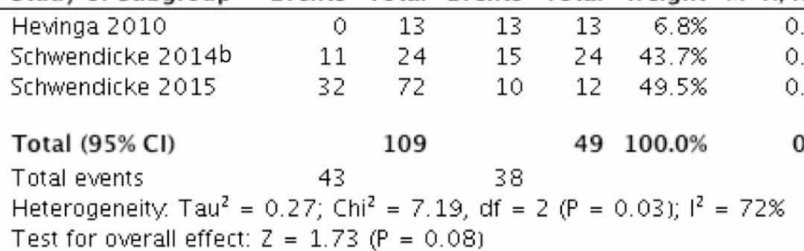

$0.04[0.00,0.56]$

$0.73[0.43,1.25]$

$0.53[0.37,0.77]$

$0.51[0.24,1.09]$

Test for overall effect: $\mathrm{Z}=1.73(\mathrm{P}=0.08$

- Catastrophic fracture of shallow lesions

SCE CCE Risk Ratio

Study or Subgroup Events Total Events Total Weight M-H, Random, 95\% CI

$\begin{array}{lllllll}\text { Schwendicke 2014b } & 7 & 12 & 10 & 12 & 30.9 \% & 0.70[0.41,1.20]\end{array}$

Schwendicke 2015

$\begin{array}{lllll}32 & 72 & 10 & 12 & 69.1 \%\end{array}$

$0.53[0.37,0.77]$

Total $(95 \% \mathrm{Cl})$

Total events

84

$24100.0 \%$

$0.58[0.43,0.78]$

Heterogeneity. $\mathrm{Tau}^{2}=0.00 ; \mathrm{Chi}^{2}=0.70, \mathrm{df}=1(\mathrm{P}=0.40) ; \mathrm{I}^{2}=0 \%$

Test for overall effect: $Z=3.55(\mathrm{P}=0.0004)$

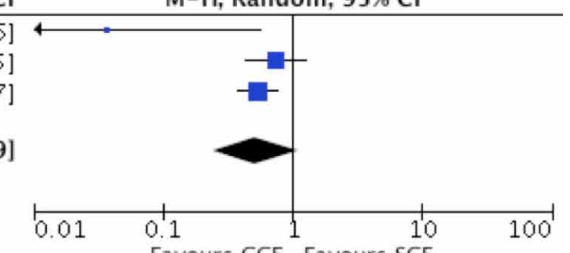

Favours CCE Favours SCE

- Catastrophic fracture of deep lesions

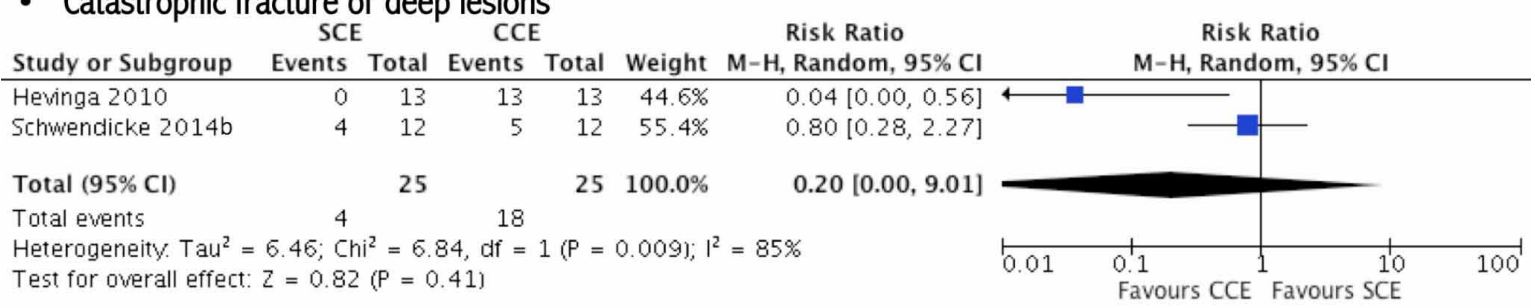

Fig. 5. Quantitative meta-analyses for risk of catastrophic failure comparing SCE vs. CCE, overall analysis and analysis according to lesion depth. $\mathrm{RR}, 95 \% \mathrm{Cl}$, forest plots, heterogeneity parameter (I2) as well as overall statistics (Z, P) are shown. 
-Risk of bias. Detailed risk of bias assessments for all included studies are summarized in Table I. Risk of bias was low for three studies (Hevinga et al.; Schwendicke et al., 2014a,b) and medium for two studies (Schwendicke et al., 2015b, 2017).

\section{DISCUSSION AND CONCLUSION}

Complete caries removal is associated with a relatively high risk of pulpal exposure and of postoperative pulpal symptoms (Ricketts et al.; Schwendicke et al., 2013a). Contrastingly, after selective caries removal the caries-affected, sclerotic dentin may compromise the bond strength and the reliability of restorations (de Almeida Neves et al., 2011). The present systematic review, thus, investigated the mechanical properties of teeth restored after SCE and CCE. Based on a very small number of in vitro studies significantly lower fracture resistances and higher cuspal deflections were found after SCE, whereas significantly higher risks of catastrophic failure were detected after CCE.

Previously, it was observed that the deeper a cavity is prepared the more vertical forces are transformed into tensile forces (Bell et al., 1982; Goel et al., 1992). Furthermore, it was observed that higher tensile forces are associated with higher potentials for fracture (Goel et al.). These findings were also in agreement with the results of another study. For occlusal and posterior approximal preparations, fracture resistance decreased the deeper the cavity was prepared (Mondelli et al., 1980). Consequently, it might be speculated that SCE increases fracture resistance compared to CCE as less dentin has to be removed. However, in the present review teeth restored after SCE presented significantly lower fracture resistance compared to teeth restored after CCE. Only for shallow lesions no significant difference could be observed. An explanation to this behaviour might be found in the fact that after SCE leathery or soft dentin is left at the pulpal wall. This residual layer of softer dentin might reduce the adhesion between the restoration and the tooth compared to the adhesion between a restoration and sound dentin after CCE (Yoshiyama et al.; Perdigão) and might, thus, compromise the resistance of the restored tooth due to its higher deformability. Furthermore, it might be speculated that the effect of higher tensile forces in deeper cavities (after CCE) might be superimposed by the lower adhesive bonds after SCE, resulting in a significantly lower fracture resistance after SCE.
Nonetheless, the results on fracture resistance show a great heterogeneity. This can also be seen in the cavity designs and tooth types being used in the included studies. Occlusal preparations in molars (Hevinga et al.) as well as posterior approximal preparations in premolars (Schwendicke et al., 2014b, 2015b) were included. Since the design of a cavity influences the mechanics of the tooth-restoration-complex (Arunpraditkul et al., 2009) and, thus, its complexity as a biomechanical system (Lin et al., 2001), the conclusion on fracture resistance seems to be limited.

In the present study cuspal deflection at 200 and $400 \mathrm{~N}$ was significantly higher for teeth restored after SCE compared to CCE. Although, more dentin is removed after CCE compared to SCE, resulting in larger preparations, this does not seem to increase the bending of the cusps more than after SCE. However, the size of the cavity does not seem to be the dominant factor when comparing SCE to CCE. The reduced resin composite bonding strength in SCE seems to be more relevant. Teeth with extensive loss of hard tissues are stabilized by successful adhesive restorations (Bremer \& Geurtsen, 2001). This stabilisation is presumably lacking when bonding on a residual layer of softer dentin (as discussed above) resulting in an increased separation of cusps when loaded. However, it is important to state that clinical studies cannot confirm this finding (Schwendicke et al., 2013b) and that only one of the studies aimed to specifically assess the effect of SCE and CCE on cuspal deflection (Schwendicke et al., 2014b), whereas the other studies aimed to assess the effect of different restorative materials when using SCE (Schwendicke et al., 2015b).

Although deeper preparations in CCE did not affect fracture resistance and cuspal deflection as negatively as SCE, it did increase the risk of catastrophic fractures compared to SCE. SCE presented a (significantly) lower risk of catastrophic failure compared to CCE. This could also be observed in previous studies. Finite element analyses have shown that the stress distribution changed when cavities were deeper, increasing the stress adjacent to the pulpal wall and the potential for deep cuspal fracture (Goel et al.; Lin et al.). Thereby, the integrity of the dental hard tissue is affected rather than the integrity of the restoration. Thus, for teeth treated with CCE increased fracture resistance seemed to result in more catastrophic failures. In contrast, for teeth treated with SCE - presenting lower fracture resistance - it is more likely that the fracture is repairable, giving the option for restoring again and retaining the tooth. 
The most important limitation of the present review is that most of the included studies were performed by the same working group. The studies presented strong similarities concerning methods to create artificial caries, teeth/cavity dimensions and aging protocols. Of course, this facilitates direct and indirect comparisons, however, this could also be a source of bias. For example, if the internal or external validity of the study design is lacking, this bias would probably be present in all studies of the same working group. In addition, it should be stated that although all of the included studies investigated SCE, not all of them intended to specifically compare SCE and CCE: Two of them primarily investigated different bonding systems (Schwendicke et al., 2015b) or lined and non-lined resin composites (Schwendicke et al., 2017).

Although in vitro studies were specifically relevant to assess mechanical properties, these models also present some disadvantages. The present in vitro models were not able to simulate the remineralization and hardness changes which can be observed in vivo when carious tissue is left under an adequately sealed restoration (Bjørndal et al., 1997; Maltz et al., 2002). Therefore, over the time the mechanical performance of the tooth-restoration complex in vitro is likely to differ from the performance in vivo. In addition, in the studies in which artificial caries was left at the pulpal wall (Schwendicke et al., 2014a,b, 2015b, 2017) smear layers were not simulated. This might have changed the adhesion to this wall. The adhesion might also be influenced by the lack of bacterial infection and enzymatic degradation being present in a natural caries lesion (Schwendicke et al., 2015a).

In the present study the Cochrane Collaboration's tool for assessing risk of bias was specifically adjusted for in vitro studies. For this, the criteria were complemented by relevant criteria being identified in previous systematic reviews of in vitro studies (Moraes et al.; Soares et al.). Thus, risk of bias assessment consisted of eleven criteria. Overall risk of bias was low for three studies (Hevinga et al.; Schwendicke et al., 2014a,b) and medium for two studies (Schwendicke et al., 2015b, 2017). Nonetheless, the included studies still presented unclear or high risks for some of the domains. Lack of information about sample size calculation and selection bias were the main reasons for high risk, and should be carefully considered in future in vitro studies.

Within the limitation of this systematic review, it can be concluded that the mechanical behaviour of restored teeth is affected by the excavation strategy. Although there is a tendency for lower fracture resistance and higher cuspal deflection after SCE, there is also a lower risk of catastrophic failure when compared to CCE. Clinically, the latter aspect might be the most relevant, because a non-catastrophic failure allows to repair or replace the restoration retaining the tooth, whereas a catastrophic failure, results in the end of the restorative cycle for the affected tooth. Nonetheless, results should be interpreted with caution, due to the low numbers of in vitro studies.

CORRAL-NÚÑEZ, C.; MEYER-LUECKEL, H.; ARAYA-CABELLO, I.; MARTIN, J.; ESTAY, J. \& WIERICHS, R. J. Propiedades mecánicas de dientes restaurados tras excavación selectiva de caries. Revisión sistemática y metaanálisis. Int. J. Odontostomat., 15(1):204-212, 2021.

RESUMEN: El objetivo de este estudio fue revisar sistemáticamente la literatura de estudios in vitro que comparan las propiedades mecánicas de los dientes restaurados después de la excavación selectiva de caries (ESC) y la excavación de caries completa (ECC). Se realizaron búsquedas sistemáticas en las bases de datos electrónicas PubMed / MEDLINE y EMBASE. Los estudios in vitro que investigan las propiedades mecánicas de los dientes restaurados después de la ESC fueron verificados de forma independiente por dos autores. Los criterios de inclusión fueron: (1) realizar ESC (2) mencionar que los dientes fueron posteriormente restaurados y (3) evaluar las propiedades mecánicas de los dientes restaurados. El metanálisis se realizó con y sin discriminación entre lesiones superficiales y profundas. De 1.859 estudios potencialmente elegibles, se seleccionaron 14 para el análisis de texto completo y 5 se incluyeron en el metanálisis. La resistencia a la fractura fue significativamente menor después de ESC que después de CCE en el análisis general (DME [IC del $95 \%$ ] $=-1,62[-3,04,-0,20])$ y para la lesión profunda (DME [IC del $95 \%]=-1,62[-2,62,-0,61])$, mientras que la deflexión de las cúspides a 200 y $400 \mathrm{~N}$ fue significativamente mayor después de ESC que después de CCE para análisis discriminados y no discriminados. Además, para las lesiones superficiales, el riesgo de fractura catastrófica fue significativamente menor después de ESC que de CCE (RR [IC $95 \%]=0,58[0,43,0,78])$. Los estudios incluidos presentaron riesgo de sesgo bajo y medio. El comportamiento mecánico de los dientes restaurados parece verse afectado por la estrategia de excavación. Aunque existe una tendencia a una menor resistencia a la fractura y una mayor deflexión de la cúspide después de la ESC, existe un menor riesgo de falla catastrófica en comparación con la CCE. Sin embargo, esta conclusión se basa en muy pocos estudios in vitro.

PALABRAS CLAVE: dientes, propiedades mecánicas, caries, revisión sistemática. 


\section{REFERENCES}

Arunpraditkul, S.; Saengsanon, S. \& Pakviwat, W. Fracture resistance of endodontically treated teeth: three walls versus four walls of remaining coronal tooth structure. J. Prosthodont., 18(1):49-53, 2009.

Bell, J. G.; Smith, M. C. \& de Pont, J. J. Cuspal failures of MOD restored teeth. Aust. Dent. J., 27(5):283-7, 1982.

Bjørndal, L. \& Kidd, E. A. M. The treatment of deep dentine caries lesions. Dent. Update, 32(7):402-4, 407-10, 413, 2005.

Bjørndal, L.; Larsen, T. \& Thylstrup, A. A clinical and microbiological study of deep carious lesions during stepwise excavation using long treatment intervals. Caries Res., 31(6):411-7, 1997.

Bremer, B. D. \& Geurtsen, W. Molar fracture resistance after adhesive restoration with ceramic inlays or resin-based composites. Am. J. Dent., 14(4):216-20, 2001.

de Almeida Neves, A.; Coutinho, E.; Cardoso, M. V.; Lambrechts, P. \& Van Meerbeek, B. Current concepts and techniques for caries excavation and adhesion to residual dentin. J. Adhes. Dent., 13(1):7-22, 2011.

Fusayama, T.; Okuse, K. \& Hosoda, H. Relationship between hardness, discoloration, and microbial invasion in carious dentin. J. Dent. Res., 45(4):1033-46, 1966.

Goel, V. K.; Khera, S. C.; Gurusami, S. \& Chen, R. C. Effect of cavity depth on stresses in a restored tooth. J. Prosthet. Dent., 67(2):174-83, 1992.

Hevinga, M. A.; Opdam, N. J.; Frencken, J. E.; Truin, G. J \& Huysmans, M. C. Does incomplete caries removal reduce strength of restored teeth? J. Dent. Res., 89(11):1270-5, 2010.

Higgins, J. P. T. \& Green, S. G. (Eds.). Cochrane Handbook for Systematic Reviews of Interventions. Version 5. 10 (updated March 2011). West Sussex, The Cochrane Collaboration, 2011.

Higgins, J. P. T. \& Thompson, S. G. Quantifying heterogeneity in a meta-analysis. Stat. Med., 21(11):1539-58, 2002.

Lin, C. L.; Chang, C. H. \& Ko, C. C. Multifactorial analysis of an MOD restored human premolar using auto-mesh finite element approach. J. Oral Rehabil., 28(6):576-85, 2001.

Maltz, M.; de Oliveira, E. F.; Fontanella, V. \& Bianchi, R. A clinical, microbiologic, and radiographic study of deep caries lesions after incomplete caries removal. Quintessence Int., 33(2):1519, 2002.

Maltz, M.; Henz, S. L.; de Oliveira, E. F. \& Jardim, J. J. Conventional caries removal and sealed caries in permanent teeth: a microbiological evaluation. J. Dent., 40(9):776-82, 2012.

Mantel, N. Chi-square tests with one degree of freedom; extensions of the Mantel-Haenszel procedure. J. Am. Stat. Assoc., 58(303):690-700, 1963.

Mondelli, J.; Steagall, L.; Ishikiriama, A.; de Lima Navarro M. F. \& Soares, F. B. Fracture strength of human teeth with cavity preparations. J. Prosthet. Dent., 43(4):419-22, 1980.

Moraes, A. P.; Sarkis-Onofre, R.; Moraes, R. R.; Cenci, M. S.; Soares, C. J. \& Pereira-Cenci, T. Can silanization increase the retention of glass-fiber posts? A systematic review and metaanalysis of in vitro studies. Oper. Dent., 40(6):567-80, 2015.

Page, M. J. \& Moher, D. Evaluations of the uptake and impact of the Preferred Reporting Items for Systematic reviews and MetaAnalyses (PRISMA) Statement and extensions: a scoping review. Syst. Rev., 6(1):263, 2017.

Paris, S. \& Meyer-Lueckel, H. Paradigm Shift in Cariology. In: Meyer-Lueckel, H.; Paris, S. \& Ekstrand, K. R. (Eds.). Caries Management - Science and Clinical Practice. Stuttgart, Georg Thieme Verlag; 2013.

Perdigão, J. Dentin bonding-variables related to the clinical situation and the substrate treatment. Dent. Mater., 26(2):e24-e37, 2010.
Ricketts, D.; Lamont, T.; Innes, NP.; Kidd, E \& Clarkson, J.E. Operative caries management in adults and children. Cochrane Database Syst. Rev., (3):CD003808, 2013.

Schwendicke, F.; Dörfer, C. E. \& Paris, S. Incomplete caries removal: a systematic review and meta-analysis. J. Dent. Res., 92(4):306-14, 2013a.

Schwendicke, F.; Eggers, K.; Meyer-Lueckel, H.; Dörfer, C.; Kovalev, A.; Gorb, S \& Paris, S. In vitro Induction of residual caries lesions in dentin: comparative mineral loss and nano-hardness analysis. Caries Res., 49(3):259-65, 2015a.

Schwendicke, F.; Frencken, J. E.; Bjørndal, L.; Maltz, M.; Manton, D. J.; Ricketts, D.; Van Landuyt, K.; Banerjee, A.; Campus, G.; Doméjean, S.; et al. Managing carious lesions: consensus recommendations on carious tissue removal. Adv. Dent. Res., 28(2):58-67, 2016.

Schwendicke, F.; Kern, M.; Blunck, U.; Dörfer, C.; Drenck, J. \& Paris, S. Marginal integrity and secondary caries of selectively excavated teeth in vitro. J. Dent., 42(10):1261-8, 2014a

Schwendicke, F.; Kern, M.; Dörfer, C.; Kleemann-Lüpkes, J.; Paris, S. \& Blunck, U. Influence of using different bonding systems and composites on the margin integrity and the mechanical properties of selectively excavated teeth in vitro. J. Dent., 43(3):327-34, 2015b.

Schwendicke, F.; Kern, M.; Meyer-Lueckel, H.; Boels, A.; Doerfer, C. \& Paris, S. Fracture resistance and cuspal deflection of incompletely excavated teeth. J. Dent., 42(2):107-13, 2014b.

Schwendicke, F.; Kniess, J.; Paris, S. \& Blunck, U. Margin integrity and secondary caries of lined or non-lined composite and glass hybrid restorations after selective excavation in vitro. Oper. Dent., 42(2):155-64, 2017.

Schwendicke, F.; Meyer-Lueckel, H.; Dörfer, C. \& Paris, S. Failure of incompletely excavated teeth--a systematic review. J. Dent., 41(7):569-80, 2013b.

Soares, F. Z. M.; Follak, A.; da Rosa, L. S.; Montagner, A. F.; Lenzi, T. L. \& Rocha, R. O. Bovine tooth is a substitute for human tooth on bond strength studies: A systematic review and metaanalysis of in vitro studies. Dent. Mater., 32(11):1385-93, 2016.

Yoshiyama, M.; Tay, F. R.; Doi, J.; Nishitani, Y.; Yamada, T.; Itou, K.; Carvalho, R. M.; Nakajima, M. \& Pashley, D. H. Bonding of self-etch and total-etch adhesives to carious dentin. J. Dent. Res., 81(8):556-60, 2002.

Corresponding author:

Camila Corral Núñez

Department of Restorative Dentistry Faculty of Dentistry

Universidad de CHILE

Santiago

CHILE

Email: camila.corral@odontologia.uchile.cl 